\title{
Gadolinyumun Tatlı Su Omurgasızı Dreissena polymorpha Üzerindeki Biyokimyasal Etkileri
}

\author{
Osman Serdar ${ }^{1}$, Numan Yıldırım ${ }^{2 *}$, Şule Tatar ${ }^{3}$, Nuran Cikcikoğlu Yıldırım ${ }^{3}$ \\ ${ }^{I}$ Munzur Üniversitesi, Su Ürünleri Fakültesi TR62000 Tunceli, Türkiye \\ ${ }^{2}$ Munzur Üniversitesi, Tunceli Meslek Yüksekokulu, Bitkisel ve Hayvansal Üretim Bölümü, Organik Tarım Programı \\ TR62000 Tunceli, Türkiye \\ ${ }^{3}$ Munzur Üniversitesi, Tunceli Meslek Yüksekokulu, Kimya ve Kimyasal İsleme Teknolojileri Bölümü, Laboratuvar \\ Teknolojisi Programı, TR62000 Tunceli, Türkiye

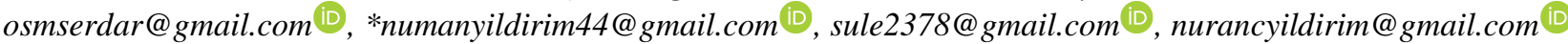 \\ Makale gönderme tarihi: 02.02.2021, Makale kabul tarihi: 24.05.2021
}

\begin{abstract}
$\mathrm{Bu}$ çalışma, metabolik ve oksidatif stres biyobelirteçlerinin analizi yoluyla, su kirliliğinin iyi bir biyoindikatörü olarak kabul edilen tatlı su omurgasızı Dreissena polymorpha üzerindeki Gadolinyum (Gd) toksisitesini değerlendirmeyi amaçlamaktadır. Öncelikle çalışmamızda Gd'nin $D$. polymorpha üzerindeki LC50 değeri belirlenmiştir. D. polymorpha, kontrollü koşullar altında 24 ve 96 saatlik bir süre boyunca üç letal olmayan $\mathrm{Gd}$ konsantrasyonuna (1/20, 1/10 ve 1/5 LC50 değerine) maruz bırakılmıştır. TBARS ve CYP1A1 seviyeleri ELISA kiti kullanılarak belirlenmiştir. CYP1A1 ve TBARS düzeylerinin tüm gruplarda 24. ve 96. saatte kontrol grubuna göre arttığı görülmüş̧ür. Bu sonuçlar, Gd'nin tatı su omurgasızları, D. polymorpha için bir risk olarak kabul edilebileceğini ve bu nedenle alıcı ortamlara deşarjının denetlenmesi gerektiğini göstermektedir.
\end{abstract}

Öz

Anahtar Kelimeler: CYP1A1, dreissena polymorpha, gadolinyum, TBARS

\section{Biochemical Effects of Gadolinium on a Freshwater Invertebrate Dreissena Polymorpha}

\begin{abstract}
This study aims to assess the toxicity of Gadolinium (Gd) on a freshwater invertebrate Dreissena polymorpha, considered a good bioindicator of aquatic pollution, through the analysis of metabolic and oxidative stress markers. Firsly, LC50 value of Gd for D. polymorpha was determined in our study. D. polymorpha were exposed to the three sublethal Gd concentrations (1/20, 1/10 and 1/5 of LC50 value) for a period of 24 and 96 hours under controlled conditions. TBARS and CYP1A1 levels were determined by using ELISA kit. The CYP1A1 and TBARS levels was found to be increased in the all groups at 24 and $96 \mathrm{~h}$ When compared to control group. These results show that $\mathrm{Gd}$ can be considered a risk for freshwater invertebrate, $D$. polymorpha and as such its discharge in the receiving environment should be supervised.
\end{abstract}

Keywords: CYP1A1, dreissena polymorpha, gadolinyum, TBARS

\section{GİRIŞ̧}

Nadir toprak elementleri (NTE'ler) doğal olarak çevreye dağılmıştır ve dünya çapında tarımda ve yüksek teknoloji malzemelerinde giderek daha fazla kullanılmaktadır, bu nedenle antropojenik kirlilik ve çevresel riskleri arttırmaktadır (BergstenTorralba ve ark., 2020).

NTE'ler, lantanit serisinin 15 elementini, Lantan ila Lutetium, Scandiumve Yttrium'u içermektedir. NTE'ler, genellikle "+3" oksidasyon durumunda benzer kimyasal özelliklere sahiptir ve nadir olarak adlandırılsalar da, bazıları doğada kadmiyum veya selenyumdan daha fazladır (Gwenzi ve ark., 2018; Xu ve ark., 2017; Gonzalez ve ark., 2015). Günümüzde, tarımsal ve teknolojik endüstrilerdeki NTE'lere, özellikle elektrikli arabalar, akıllı telefonlar, TV'ler ve güçlü mıknatıslar gibi yüksek teknoloji ürünlerine küresel 
bir bağımlılık vardır. Antropojenik NTE'lerin çevreye önemli giriş yollarından biri tarımda gübre uygulamasıdır (Balaram, 2019; Kulaksız ve Bau, 2013).

NTE'lerin suda yaşayan organizmalar üzerindeki toksisitesi tam olarak anlaşılmamıştır ve en çok çalışılan 17 element $\mathrm{La}, \mathrm{Ce}, \mathrm{Gd}$ ve Y'dir (Blinova ve ark., 2020; Pagano ve ark., 2015). Ca ile rekabet, $\mathrm{Mg}$ ikamesi veya fosfatlar veya karbonatlarla çökeltme dahil olmak üzere lantanitleri inhibe edici etki için farklı mekanizmalar daha önce gözlemlenmiştir. (Sneller ve ark., 2000). Bunun yanı sira, bazı test ortamlarında toksisiteye neden olan serbest antanit konsantrasyonunun, $\mathrm{pH}$ artışı ile büyük ölçüde azaldığı da gözlenmiştir (Weltje ve diğerleri, 2004). Bu nedenle, metal engelleyici etkiler yalnızca doğrudan toksisitelerine bağlı değildir, aynı zamanda ligandlarla kompleksleșme ve diğer metallerle rekabet, etkilerinin incelenmesine müdahale edebilir (El-Akl ve ark., 2015).

NTE'lerin, konsantrasyonlarına ve maruz kalan organizmalara bağlı olarak toksik etkiler veya büyümeyi uyarıcı etki üretebildiği bilinmektedir (Bergsten-Torralbaa, 2020). Lantanitlerin çevreye girişi, genellikle $\mathrm{ng} \mathrm{L}^{-1}$ aralığında bir konsantrasyona neden olur (Kulaksiz ve Bau, 2013; Klaver ve ark., 2014; Hatje ve ark., 2016). Klinik analizlerde Gd bazlı kontrast ajanların (CABGd) kullanılması nedeniyle, birçok çalışma, sucul sistemlerde antropojenik aktivitelerin bir göstergesi olarak Gd'nin potansiyel kullanımını doğrulamaktadır (Elbaz-Poulichet ve ark., 2002; Knappe ve ark., 2005).

Oksidatif stres, reaktif oksijen türlerinin (ROS) aşırı birikmesi nedeniyle gelişir. Kabaca tüm biyotik ve abiyotik stresleri gerçekleştiren fizyolojik ve kimyasal olayları kontrol eder (Demidchik, 2015). Oksidatif strese yol açan redoks dengesizliğinde çeşitli NTE'lerin rolü, hem bitki hem de hayvan modellerinde yürütülen bir dizi bağımsız çalışmada gösterilmiştir ve pek çok NTE'nin oksidatif strese neden olduğu rapor edilmiştir (Tseng ve ark. „2012; Wang ve ark., 2012; Zhao ve ark., 2013).

Tiobarbitürik asit reaktif maddeler (TBARS)

olarak ölçülen lipid peroksidasyonu, çeşitli çalışmalarda farklı çevresel kirleticilere yanıt olarak oksidatif stresin bir belirteci olarak s1klıkla kullanılmıştır (Almroth ve ark., 2005; Choi and Oris
2000; Oakes and Van Der Kraak 2003; Roméo ve ark., 2000).

Hem laboratuar hem de arazi koşullarında en kapsamlı şekilde araştırılan suda belirli ksenobiyotik türlerinin varlığına en erken biyolojik tepkilerinden biri olan bir biyobelirteç de hepatik karışık fonksiyonun geniş ailesine ait olan ve Faz I ksenobiyotik biyotransformasyonda rol oynayan oksidaz enzimlerinden biri olan sitokrom P450'dir. (Whyte ve ark., 2000; Široka ve Drastichova 2004). Sitokromlar P450 (CYP), ksenobiyotiklerin metabolizmasinda ve degredasyonunda rol alan monooksijenazlardır (Guengerich, 2000). CYP450'ler arasında, CYP1A1, geniş bir ksenobiyotik gurubu tarafindan yüksek oranda indüklendiği için büyük ilgi görmüştür (Dension ve ark., 2003). CYP1A1'in regülasyonu kapsamlı bir şekilde incelenmiştir, ancak tam olarak anlaşılmamıştır. Stresli koşullar da dahil olmak üzere fizyolojik koşullardaki değişiklikler, CYP1A1 ekspresyonunu artırdığ 1 bilinmektedir (AnwarMohamed ve ark, 2009).

D. polymorpha güçlü bir oksidatif savunmaya sahip olduğundan ve ksenobiyotiklere nispeten yüksek bir dirence sahip olduğundan, ekotoksikolojik deneyler yapmak için yaygın olarak kullanılmaktadır (Faria ve ark., 2009).

Bildiğimiz kadarıyla mevcut çalışma gadolinyumun (Gd)'ın Dreissena polymorpha üzerindeki toksik etkilerinin CYP1A1 ve TBARS seviyelerindeki değişikliklerin incelendiği çok az sayıdaki çalışmadan birsidir.

\section{MATERYAL VE METOD}

D. polymorpha bireyleri Firat Nehri'nden

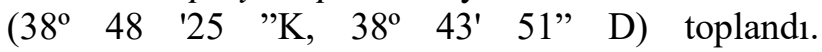
Organizmalar laboratuvara hızlı bir şekilde plastik şişelerde getirildi. Deneylerde kullanılmadan önce 15 gün $18{ }^{\circ} \mathrm{C}^{\prime}$ de tutulan bir odada $20 \mathrm{~L}$ havalandırmalı bir akvaryumda doğal yaşam koşullarına benzer ortam dizayn etmek için 12 saatlik bir aydınlık: karanlık döngüsünde plankton ile beslendi. Çalışma için benzer gelişim aşamasındaki organizmalar seçilmiş ve deneysel çalışma süresince beslenmemiş ve 24 saatte bir kontrol edilmiş, ölü bireyler sayılmış ve deneysel akvaryumdan çıkarılmıştır. Hareketsizlik ölüm kriteri olarak kabul edilmiştir.

LC50'yi belirlemek için standart bir test değeri (APHA, 1998) kullanılmıştır. LC50 değeri 
$332.20 \mathrm{mgL}^{-1}$ olarak belirlenmiștir. Ardından $D$. polimorpha bireyleri, 24 ve 96 saat boyunca üç subletal Gd konsantrasyonuna (LC50 değerinin 1/20, $1 / 10$ ve $1 / 5$ oranlarında) maruz bırakılmıştır. Gd (Gadolinyum (III) klorür hekzahidrat, $\mathrm{GdCl}_{2}\left(\mathrm{H}_{2} \mathrm{O}\right)_{6}$ içeren solüsyonlar sentetik olarak hazırlanmıştır. Dört deney grubu tasarlanmış olup: Kontrol grubuna hiç Gd uygulaması yapılmamış, A grubuna: 17 $\mathrm{mgL}^{-1}$, B: $33 \mathrm{mgL}^{-1}$, C: $66 \mathrm{mgL}^{-1}$ Gd uygulamas1 yapılmıştır.

Analizler için numuneler önce tartılmış ve $1 / 5$ ağırlık/hacim oranında PBS tamponu (fosfat ile tamponlanmış tuz çözeltisi) eklenerek ve buzlu homojenizatör kullanılarak homojenize edilmiștir. Homojenleştirilmiş numuneler, soğutulmalı santrifüjde 17.000 rpm'de 15 dakika santrifüj edilmiş; Elde edilen süpernatanlar hemen $-70{ }^{\circ} \mathrm{C}$ 'de derin dondurucuya alınmış ve ölçümleri yapılana kadar orada tutulmuştur. Cayman Chemical şirketinden satın alınan ELISA kiti kullanılarak dokulardaki TBARS seviyeleri belirlenmiştir (katalog numaras1 TBARS: 10009055). CYP1A1, Cusabio şirketinden satın alınan ELISA kiti kullanılarak belirlenmiştir (katalog no: CSBEL006395FI).

İstatistiksel analiz için SPSS PASW Statistics 18 versiyonu kullanılmıştır. Aynı maruziyet süresinde $\left({ }^{\mathrm{abc}} \mathrm{p}<0.05\right)$ üç uygulama grubundaki (A, B, C) istatistiksel farkl11kkları değerlendirmek için tek yönlü ANOVA ve Duncan'ın çoklu aralık testleri kullanılmıştır. Aynı uygulama grubunda maruz kalma süreleri arasındaki farklılıkları karşılaştırmak için iki uçlu bağımsız $\mathrm{T}$ testi kullanılmıştır $(* \mathrm{p}<0.05)$.

\section{BULGULAR \\ CYP1A1 Düzeyleri}

24 ve 96. Saat boyunca Gd maruziyetinin sonrasinda CYP1A1 enzim aktivitesinin kontrol grubu ile karş1laştırıldığında, tüm gruplarda arttığı bulundu $(\mathrm{p}<0.05)$. Maruz kalma süreleri karşılaştırıldığında, istatistiksel olarak anlamlı farkl111k sadece B grubunda bulundu $(\mathrm{p}<0.05)$ (Şekil 1).

\section{TBARS Seviyeleri}

Gd maruziyetinde kontrol grubu ile karşılaştırıldığında TBARS düzeylerinin 24. ve 96. saatte tüm gruplarda arttığ 1 saptand $1(\mathrm{p}<0.05)$. Maruz kalma süreleri karşılaştırıldığında sadece $B$ grubunda istatistiksel olarak anlamlı fark bulundu (p $<0.05$ ) (Şekil 2).

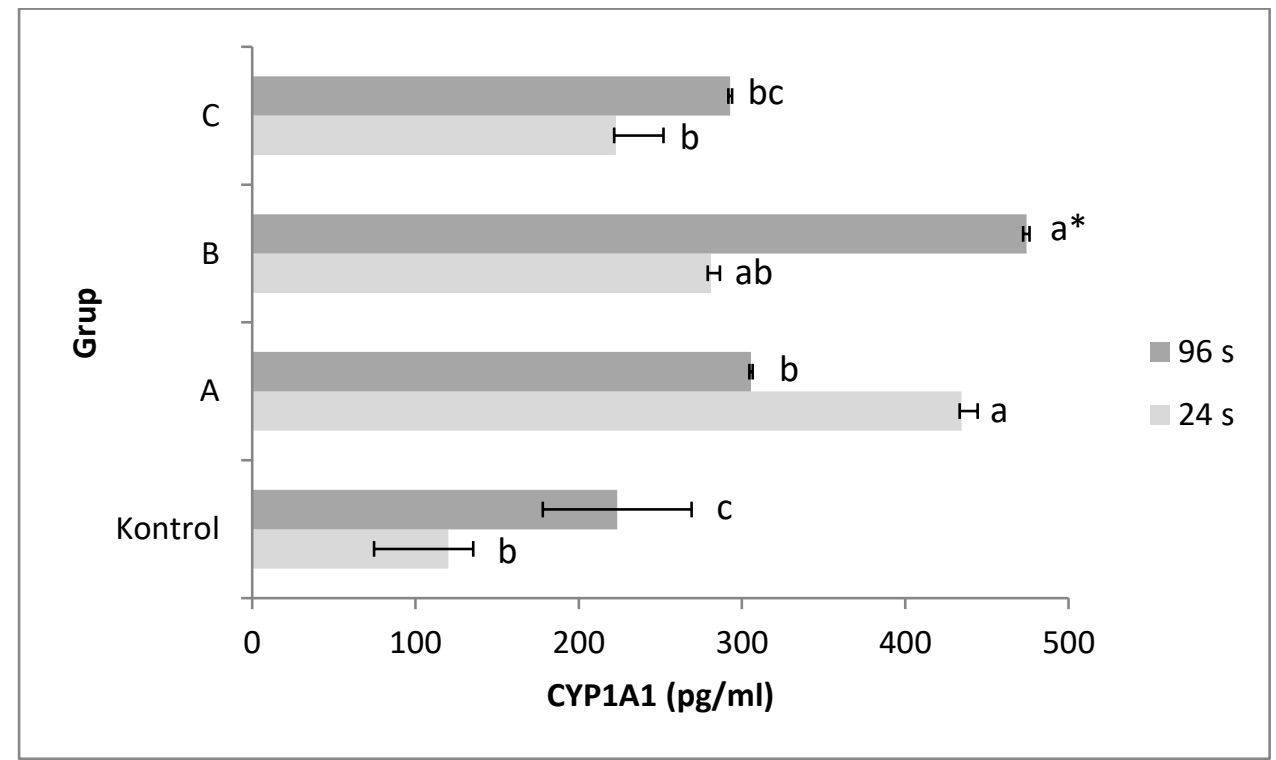

Şekil 1. Farklı dozlarda Gd uygulanan D. polymorpha'da CYP1A1 (pg / mL) enzim aktivitesindeki değişiklikler. Barlar üzerindeki farklı harfler, aynı uygulama periyodundaki gruplar arasında istatistiksel olarak anlamlı bir farkı belirtir, ${ }^{\text {abc }} \mathrm{p}<0.05$ (Duncan'ın çoklu karşılaştırma testine göre). *; aynı uygulama grubunda 24. ve 96. saatler arasındaki istatistiksel farkı gösterir (Bağımsız T-testi) 


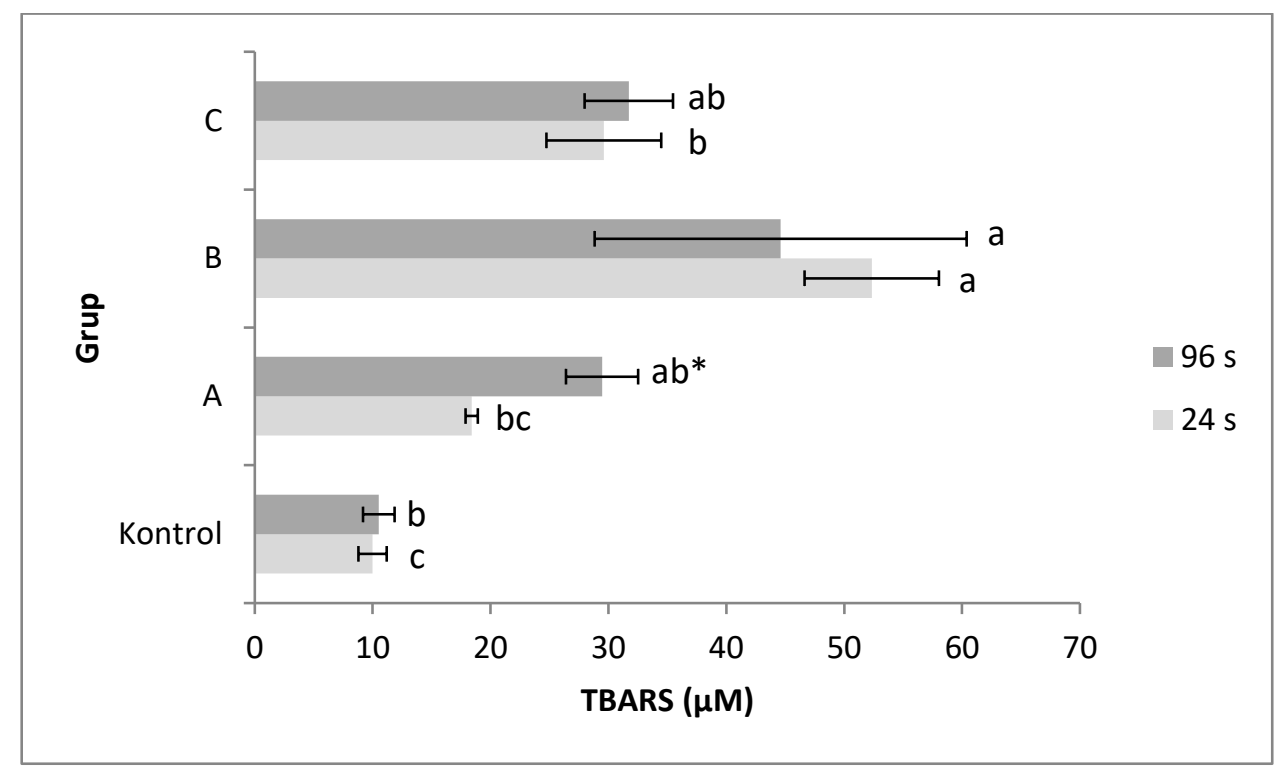

Şekil 2. Farklı dozlarda Gd uygulanan D. polymorpha'da TBARS $(\mu \mathrm{M})$ seviyelerindeki değişiklikler. Barlar üzerindeki farklı harfler, aynı uygulama periyodundaki gruplar arasında istatistiksel olarak anlamlı bir farkı belirtir, ${ }^{a b} \mathrm{p}<0.05$ (Duncan'ın çoklu karşılaştırma testine göre). *; aynı uygulama grubunda 24. ve 96. saatler arasındaki istatistiksel farkı gösterir (Bağımsız T-testi)

\section{TARTIŞMA}

Yapılan çeşitli çalışmalardan elde edilen verilere göre çeşitli metal kaynaklı sitotoksisitenin altında yatan mekanizma olarak oksidatif stres olduğunu göstermektedir (Yang ve ark., 2004; Milatovic ve ark., 2007).

Lantanid ailesinin bir üyesi olan gadolinyum (Gd), çeşitli endüstriyel ve tıbbi uygulamalarda yaygın olarak kullanılmıştır. Gd-şelatlı türevler, manyetik rezonans görüntüleme için bir kontrast ortam olarak klinik uygulamada yaygın olarak kullanılmaktadır (Adding ve ark. 2006). Gadolinyum, çok düşük konsantrasyonlarda birçok kalsiyum kanallarının önemli bir engelleyicisidir. Bunun sonucu olarak, düz, iskelet ve

kalp kaslarının kasılması gibi; sinir uyarılarının iletimi ve kan pıhtılaşması gibi pek çok fizyolojik süreçleri engelleyebilir. Aynı zamanda, $\mathrm{Ca}^{2+}$ ile aktive edilmiş $\mathrm{Mg}^{2+}$-adenozin trifosfataz, bazı dehidrojenazlar ve kinazlar ve glutatyon Stransferazlar gibi belirli enzimlerin aktivitesini de inhibe eder. Aynı zamanda, kalsiyum algılama reseptörleri üzerinde bir agonist görevi görür (Quarles ve ark., 1994). Gadolinyum ayrica bazı sitokinlerin ekspresyonunu artırabilir, mitokondriyal fonksiyonu inhibe edebilir ve oksidatif stresi indükleyebilir (Feng ve diğerleri 2010; Xia ve diğerleri, 2011).

Nadir toprak elementleri ve sucul organizmalara toksik etkileri çeşitli çalışmalarda incelenmişitr. Romero-Freire vd. (2019), hafif, orta ve ağır nadir toprak elementlerini temsil eden üç lantanit $(\mathrm{Ce}, \mathrm{Gd}, \mathrm{Lu})$ karışımının toksik etkilerini yedi farklı su türünde, yani simbiyotik bir bakteri (Aliivibrio fischeri) mikroalg (Raphidocelis subcapitata), yeşil mikroalg (Chlorella vulgaris), planktonik rotifer (Brachionus calyciflorus), ostrakod (Heterocypris incongruens), su piresi (Daphnia magna) ve zebra balığı (Danio rerio) çalışmıştır. Elde edilen sonuçlara göre, testin başlangicından itibaren tüm test ortamlarında lantanit içeriğinin zamanla azaldığını öngörmüştür. Lantanitlerin başlica toksik etkilerinin A. fischeri, $R$. subcapitata ve $B$. calyciflorus üzerine olduğu bulunmuştur. Yapılan bir başka çalışmada, beş lantanidin ( $\mathrm{La}, \mathrm{Ce}, \mathrm{Pr}, \mathrm{Nd}$ ve $\mathrm{Gd}$ ) toksisitesi, 21 gün boyunca üç suda yaşayan mikrokabuklular (Thamnocephalus platyurus, Daphnia magna ve Heterocypris incongruens) üzerinde çalışılmış ve sonuçlar lantanitlerin kabuklular için kronik olarak toksik olduğunu göstermiştir. (Blinova ve ark., 2018). Bu çalışmada ise Gd'nin bir tatlısu omurgasızı olan Dreissena polymorpha üzerindeki toksik etkilerinin araştırılması amaçlanmıştır. 
TBARS, oksidatif stresi değerlendirmek için indirekt bir yöntemdir, reaktif oksidan radikaller ile hücrenin lipid membranı arasındaki etkileşimi temsil eder. NTE'lere in vivo veya in vitro maruziyetin lipid peroksidasyonu, ROS oluşumu, proinflamatuar aracıların üretimi ve glutatyon peroksidaz (GPx), katalaz (CAT) ve süperoksit dismutaz (SOD) gibi antioksidan enzimlerin aktivasyonu ile ilişkili olduğu bulunmuştur (Pagano ve ark., 2015). Pereira ve ark., (2012) tarafindan yapılan bir çalışmada Nefrektomi sonrası Gd uygulanan sıçanlarda TBARS seviyelerinin arttığ bulunmuştur bu durum Gd'nin oksidatif streste bir artışı neden olduğunu düşündürmüştür. Cho ve diğerleri, (2014) ise; Gd maruziyetine bağlı olarak insan lenfositlerinde ROS seviyelerinin arttığını bulmuşlardır. Pereira vd. (2012) sıçan kortikal nöronlarında Gd maruziyetine bağlı olarak ferritin ve transferrin aşırı doygunluğunun lipid peroksidasyonu arttırdığını göstermişlerdir. Ayrıca ROS oluşumunun da Gd uygulamasına bağlı olarak arttığı bulunmuştur (Xia ve ark. 2011). Abdelnour ve ark., (2019) nadir toprak elementlerinin (seryum ve lantan) hayvan sağlığı ve üretimi üzerindeki etkilerini araştırmış ve NTE'lerin MDA'yı düşürerek oksidatif durumu iyileştirdiğini öne sürmüşlerdir. Durmuş vd., (2015) diyetteki lantan oksit seviyelerinin $(0,100,200,300$ veya $400 \mathrm{mgkg}^{-1}$ ) yumurtlayan tavukların yumurta lipid peroksidasyonu üzerindeki etkilerini belirlemişler. Malondialdehit (MDA) serum konsantrasyonunun azaldığını bulmuşlardır.

Hanana (ve diğerleri, 2017), tatl1 su omurgasızları olan zebra midyesi Dreissena polymorpha'da $\mathrm{LaCl}_{3} \mathrm{e}$ kronik alt1 maruziyetin etkisini araştırmıştır. Biyoyararlanımını değerlendirmek için midye dokularında La konsantrasyonlarını belirlemişlerdir. Biyoyararlanıma ek olarak; oksidatif ve genetik hasar biyobelirteçleri, çoklu biyobelirteç yaklaşımı ile değerlendirilmiştir. $1250 \mu \mathrm{gL}^{-1} \mathrm{LaCl}_{3}{ }^{\prime} \mathrm{e} 28$ gün maruz kaldıktan sonra LPO'da önemli bir artış bulunmuştur. Yapılan başka bir çalışmda, $\mathrm{GdCl}_{3}$ uygulaması da çoklu biyobelirteç yaklaşımı ile 28 gün boyunca zebra midyeleri üzerinde çalışılmıştır. Bulgulara göre, $\mathrm{GdCl}_{3}$ maruziyeti sonrası SOD ve sitokrom c-oksidazın $\left(\mathrm{CO}_{1}\right)$ arttığını göstermektedir. Aynı zamanda, CAT ve GST gen ekspresyonun, lipid peroksidasyonu ve genotoksisite üzerinde hiçbir spesifik etki olmaksızın azaldığ 1 görülmüştür (Hanna ve ark., 2020).
Pinto ve ark., (2019) oksidatif stres belirteçlerinin analizi yoluyla La'nın midye Mytilus galloprovincialis üzerindeki toksisitesini değerlendirmişlerdir. Organizmalar, 28 günlük bir süre boyunca $\left(0,0.1,1,10 \mathrm{mgL}^{-1}\right)$ farkl1 $\mathrm{La}$ konsantrasyonlarına maruz bırakılmıştır.

La maruziyeti sonrası midyelerde, özellikle orta konsantrasyonlarda antioksidan savunmalar SOD ve GPx'in yanı sira biyotransformasyon enzimlerinin GST'lerinin aktivasyonu ile biyokimyasal bir cevap oluştuğu görülmüştür. GSH/GSSG'deki azalma Oksidatif stres oluştuğunun bir göstergesi olsa da oksidatif hasarın düssen lipid peroksidasyon seviyeleri ile önlendiği görülmüştür. Henriques ve ark., (2019) Gd'ye maruz kalmanın midye metabolizmasındaki azalma, oksidatif stresin indüksiyonu ve nörotoksisite dahil olmak üzere $M$. galloprovincialis'in biyokimyasal performansinı özellikle orta konsantrasyonlarda güçlü bir şekilde etkilediğini belirtmişlerdir. $\mathrm{Bu}$ çalışmada ise; TBARS düzeyleri Gd maruziyeti sonrası kontrol grubuna göre 24. ve 96. saatte tüm gruplarda artmış olduğu bulunmuştur $(\mathrm{p}<0.05)$.

Dube ve ark, (2019) genç gökkuşağ (Oncorhynchus mykiss) alabalığındaki NTE'lerin öldürücü ve ölümcül olmayan toksisitesini incelemişlerdir. Balıklar, $15{ }^{\circ} \mathrm{C}^{\prime} \mathrm{de} 96$ saat boyunca aşağıdaki 7 farklı NTE'nin (Seryum, erbiyum, gadolinyum, lantan, neodimyum, samaryum ve itriyum) artan konsantrasyonlarına (0.064, 0.32, 1.6, 8 ve $40 \mathrm{mgL}^{-1}$ ) maruz birakılmıştır. Gökkuşağ alabalığ 1 ile gözlenen tepkilerden farklı olarak CYP1A1 gen ekspresyonunun arttığını bulmuşlardır. Sitokrom P450, işlevinin Fe'nin oksidasyon durumuna $\quad\left(\mathrm{Fe}^{2+} / \mathrm{Fe}^{3+)} \quad\right.$ bağl1 $\quad$ olduğu hemoproteinlerdir; daha toksik ve elektronegatif NTE'lerin bu redoks süreçlerine müdahale edebileceği ileri sürülmüştür. Gen ekspresyonundaki artışın, sitokrom P450 enzim aktivitesi kaybına karşı koymak için bir telafi mekanizması olabileceği düşünülmektedir. Bizim çalışmamızda da çalışmada, Gd maruziyetinde kontrol grubu ile karşılaştırıldığında, 24 ve 96 . saatte tüm gruplarda CYP1A1 enzim aktivitesinin arttığı bulunmuştur.

\section{SONUÇ}

Elde edilen sonuçlara göre, 24 ve 96 saat boyunca $\mathrm{Gd}$ uygulanan tüm grublarda bir biyotransformasyon enzimi olan CYP1A1 ile oksidatif stresin bir biyobelirteçi olan TBARS 
seviyelerinde önemli artışlar saptanmıştır. $\mathrm{Bu}$ bulgular Gd'nin $D$. polymorpha'da oksidatif stres ve toksisiteye indüklediğini göstermiştir. Ayrıca, Gd'nin tatlı su omurgasızları, D. polymorpha için bir risk olarak kabul edilebileceğini ve bu nedenle çevreye deşarjının denetlenmesi gerektiğini de göstermektedir.

\section{ÇIKAR ÇATIŞMASI BEYANI}

Yazarlar bu çalışmada herhangi bir şekilde çıkar çatışması olmadığını beyan eder.

\section{ARAŞTIRMA VE YAYIN ETİĞİ BEYANI}

Yazarlar yapılan çalışmada, araştırma ve yayın etiğine uyulduğunu beyan eder.

\section{KAYNAKLAR}

Abdelnour, S.A., Abd El-Hack, M.E., Khafaga, A.F., Noreldin, A.E., Arif, M., Chaudhry, M.T., Losacco,

C., Abdeen, A. ve Abdel-Daim, M.M. (2019). Impacts of rare earth elements on animal health and production: Highlights of cerium and lanthanum. Science of the Total Environment, 672, 1021-1032.

Adding, L.C., Gerard, L.B. ve Lars, E.G. (2006). Basic experimental studies and clinical aspects of gadolinium salts and chelates. Cardiovascular Drug Reviews, 19, 41- 56.

Almroth, B.C., Sturve, J., Berglund, A. ve Förlin, L. (2005). Oxidative damage in eelpout (Zoarces viviparus), measured as protein carbonyls and TBARS, as biomarkers. Aquatic Toxicology, 73, 171-180.

Anwar-Mohamed, A., Elbekai, R.H. ve El-Kadi, A.O.S. (2009). Regulation of CYP1A1 by heavy metals and consequences for drug metabolism. Expert Opinion on Drug Metabolism \& Toxicology, 5(5), 501-521

Balaram, V. (2019). Rare Earth Elements: a review of applications, occurrence, exploration, analysis, recycling, and environmental impact. Geoscience Frontiers, 10(4), 1285-1303.

Bergsten-Torralbaa, L.R., Magalhães, D.P., Giese, E.C., Nascimentod, C.R.S., Pinhoe, J.V.A. ve Buss, D.F. (2020). Toxicity of three rare earth elements, and their combinations to algae, microcrustaceans, and fungi. Ecotoxicology and Environmental Safety, 201, 110795.

Blinova, I., Lukjanova, A., Muna, M., Vija, H. ve Kahru, A. (2018). Evaluation of the potential hazard of lanthanides to freshwater microcrustaceans. Science of the Total Environment, 642, 1100-1107.

Blinova, I., Muna, M., Heinlaan, M., Lukjanova, A., Kahru, A. (2020). Potential Hazard of Lanthanides and Lanthanide-Based Nanoparticles to Aquatic
Ecosystems: Data Gaps, Challenges and Future Research Needs Derived from Bibliometric Analysis. Nanomaterials. 2020; 10(2):328

Choi, J. ve Oris, J.T. (2000). Evidence of oxidative stress in bluegill sunfish (Lepomis macrochirus) liver microsomes simultaneously exposed to solar ultraviolet radiation and anthracene. Environmental Toxicology and Chemistry, 19, 1795-1799.

Cho, S., Lee, Y., Lee, S., Choi, Y.J. ve Chung, H.W. (2014). Enhanced cytotoxic and genotoxic effects of gadolinium following ELF-EMF irradiation in human lymphocytes. Drug and Chemical Toxicology, 37, 440-447.

Dube, M., Auclair, J., Hanana, H., Turcotte, P., Gagnon, C. ve Gagné, F. (2019). Gene expression changes and toxicity of selected rare earth elements in rainbow trout juveniles. Comparative Biochemistry and Physiology Part C: Toxicology \& Pharmacology, 223, 88-95.

Durmuş, O. ve Bölükbaşı, Ş. (2015). Biological activities of lanthanum oxide in laying hens. Journal of Applied Poultry Research, 24, 481-488.

El-Akl, P., Smith, S. ve Wilkinson, K.J. (2015). Linking the chemical speciation of cerium to its bioavailability in water for a freshwater alga. Environmental Toxicology and Chemistry, 34 (8), 1711-1719.

Demidchik, V. (2015). Mechanisms of oxidative stress in plants: From classical chemistry to cell biology. Environmental and Experimental Botany, 109: 212228.

Elbaz-Poulichet, F., Seidel, J.L. ve Othoniel, C. (2002). Occurrence of an anthropogenic gadolinium anomaly in river and coastal waters of Southern France. Water Research, 36, 1102-1105.

Faria, M., Carrasco, L., Diez, S., Riva, M.C., Bayona, J.M. ve Barata, C. (2009). Multi-biomarker responses in the freshwater mussel Dreissena polymorpha exposed to Polychlorobiphenyls and metals. Comparative Biochemistry and Physiology Part C: Toxicology \& Pharmacology, 149, 281-288.

Feng, X., Xia, Q. ve Yuan, L. (2010). Impaired mitochondrial function and oxidative stress in rat cortical neurons: implications for gadoliniuminduced neurotoxicity. Neurotoxicology, 31, 391-98.

Gwenzi, W., Mangori, L., Danha, C., Chaukura, N., Dunjana, N. ve Sanganyado, E. (2018). Sources, behavior, and environmental and human health risks of high-technology rare earth elements as emerging contaminants. Science of the Total Environment, 636, 299-313.

Gonzalez, V., Vignati, D.A.L., Pons, M.N., MontargesPelletier, E., Bojic, C. ve Giamberini, L. (2015). Lanthanide ecotoxicity: first attempt to measure 
environmental risk for aquatic organism. Environmental Pollution, 199, 139-147.

Guengerich, F.P. (2000). Metabolism of chemical carcinogens. Carcinogenesis, 21, 345-51.

Hanana, H., Turcotte, P., Pilote, M., Auclair, J., Gagnon, C. (2017). Biomarker assessment of lanthanum on a freshwater invertebrate, Dreissena polymorpha. SOJ Biochemistry, 3(1), 1-9.

Hatje, V., Bruland, K.W. ve Flegal, A.R. (2016). Increases in anthropogenic gadolinium anomalies and rare earth element concentrations in San Francisco Bay over a 20 year record. Environmental Science and Technology, 50, 4159-4168.

Henriques, B., Coppola, F. ve Monteiro, R. (2019). Toxicological assessment of anthropogenic Gadolinium in seawater: Biochemical effects in mussels Mytilus galloprovincialis. Science of the Total Environment, 664, 626-634.

Klaver, G., Verheul, M., Bakker, I., Petelet-Giraud, E. ve Négrel, P. (2014). Anthropogenic rare earth element in rivers: gadolinium and lanthanum. Partitioning between the dissolved and particulate phases in the Rhine River and spatial propagation through the Rhine-Meuse delta (the Netherlands). Applied Geochemistry, 47, 186-197.

Knappe, A., Moller, P., Dulski, P. ve Pekdeger, A. (2005). Positive gadolinium anomaly in surface water and ground water of the urban area Berlin, Germany. Geochemistry, 65, 167-189.

Kulaksiz, S. ve Bau, M. (2013). Anthropogenic dissolved and colloid/nanoparticle-bound samarium,lanthanum and gadolinium in the Rhine River and the impending destruction of the natural rare earth element distribution in rivers. Earth and Planetary Science Letters, 362, 43-50.

Milatovic, D., Yin, Z., Gupta, R.C., Sidoryk, M., Albrecht, J., Aschner, J.L. ve Aschner, M. (2007). Manganese induces oxidative impairment in cultured rat astrocytes. Toxicological Sciences, 98, 198- 205.

Oakes, K.D. ve Van Der Kraak, G.J. (2003). Utility of the TBARS assay in detecting oxidative stress in white sucker (Catostomus commersoni) populations exposed to pulp mill effluent. Aquatic Toxicology, 63, 447-463.

Pagano, G., Guida, M., Tommasi, F. ve Oral, R. (2015). Health effects and toxicity mechanisms of rare earth elements - knowledge gaps and research prospects. Ecotoxicology and Environmental Safety, 115, 40-48.

Pereira, L.V., Shimizu, M.H., Rodrigues, L.P., Leite, C.C., Andrade, L. ve Seguro, A.C. (2012). Nacetylcysteine protects rats with chronic renal failure from gadolinium-chelate nephrotoxicity. Plos One, 7(7), e39528.
Pinto, J., Costa, M., Leite, C., Borges, C., Coppola, F., Henriques, B., Monteiro, R., Russo, T., Cosmo, A., Soares, MVN., Polese, G., Pereira, E., Freitas, R. (2019). Ecotoxicological effects of lanthanum in Mytilus galloprovincialis: Biochemical and histopathological impacts, Aquatic Toxicology, 211, 181-192.

Roméo, M., Bennani, N., Gnassia-Barelli, M., Lafaurie, M. ve Girard, J.P. (2000). Cadmium and copper display different responses towards oxidative stress in kidney of the sea bass Dicentrachus labrax. Aquatic Toxicology, 48, 185-194.

Sneller, F.E.C., Kalf, D.F., Weltje, L. ve van Wezel, A.P. (2000). Maximum Permissible Concentrations and Negligible Concentrations for Rare Earth Elements (REEs), Report 601501011. National Institute for Public Health and the Environment (RIVM), Bilthoven, The Netherlands.

Quarles, L.D, Hartle, J.E. ve Middleton, J.P. (1994). Aluminum-induced DNA synthesis in osteoblasts: mediation by a G-protein coupled cation sensing mechanism. Journal of Cellular Biochemistry, 56, $106-17$.

Romero-Freire, A., Joonas, E., Muna, M., Cossu-Leguille, C., Vignati, D. ve Giamberini, L. (2019). Assessment of the toxic effects of mixtures of three lanthanides (ce, gd, lu) to aquatic biota. Science of the Total Environment, 661, 276-284.

Siroka, Z. ve Drastichova, J. (2004). Biochemical markers of aquatic environment contamination cytochrome $\mathrm{P} 450$ in fish. A review. Acta Veterinaria Brno, 73, 123-132.

Tseng, M.T., Lu, X., Duan, X., Hardas, S.S., Sultana, R., Wu, P., Unrine, J.M., Graham, U., Butterfield, D.A., Grulke, E.A. ve Yokel, R.A. (2012). Alterationofhepaticstructure and oxidative stress induced by intravenous nanoceria. Toxicology and Applied Pharmacology, 260, 173-182.

Wang, L., Wang, W., Zhou, Q. ve Huang, X. (2014). Combined effects of lanthanum (III) chloride and acid rain on photosynthetic parameters in rice. Chemosphere, 112, 355-361.

Weltje, L., Verhoof, L.R.C.W., Verweij, W. ve Hamers, T. (2004). Lutetium speciation and toxicity in microbial bioassay: testing the free-ion model for lanthanides. Environmental Science \& Technology, 38, 6597-6604.

Whyte, J. J., Jung, R. E., Schmitt, C. J. ve Tillitt, D.E. (2000). Ethoxyresorufin-O-deethylase (EROD) activity in fish as a biomarker of chemical exposure. Critical Reviews in Toxicology, 30(4), 347-570.

Xia Q, Feng X, Huang H., Du, L., Yang, X. ve Wang, K. (2011). Gadolinium-induced oxidative stress triggers endoplasmic reticulum stressin rat cortical neurons. Journal of Neurochemistry, 117, 38-47. 
Yang, S.J., Lee, J.E., Lee, K.H., Huh, J.W., Choi, S.Y. ve Cho, S.W. (2004). Opposed regulation of aluminuminduced apoptosis by glial cell line-derived neurotrophic factor and brain-derived neurotrophic factor in rat brains. Molecular Brain Research, 127, $146-149$.

Zhao, H., Hong, J., Yu, X., Zhao, X., Sheng, L., Ze, Y., Sang, X., Gui, S., Sun, Q., Wang, L. ve Hong, F. (2013). Oxidative stress in the kidney injury of mice following exposure to lanthanides trichloride. Chemosphere, 93, 875-884. 